\title{
Desempenho Logístico de Produtividade em Companhias Brasileiras Listadas na Bolsa de Nova lorque na Perspectiva do Modelo World Class Logistics
}

\begin{abstract}
Helton Cristian de Paula Doutorado em andamento em Administração pela Universidade Federal de Minas Gerais - UFMG Av. Antônio Carlos, 6622. Pampulha. Belo Horizonte/MG E-mail: helton@cead.ufop.br

Joyce Menezes da Fonseca Tonin Mestrado em andamento em Contabilidade pela Universidade Federal do Paraná UFPR Av. Prefeito Lothário Meissner, 632. Jd. Botânico. Curitiba/PR E-mail: joycemftonin@gmail.com

Ramon Kael Benassi Bachmann Mestrado em andamento em Contabilidade pela Universidade Federal do Paraná UFPR Av. Prefeito Lothário Meissner, 632. Jd. Botânico. Curitiba/PR E-mail:ramon_bach@yahoo.com.br

Romualdo Douglas Colauto Doutorado em Engenharia de Produção pela Universidade Federal de Santa Catarina UFSC Pesquisador e Professor da Universidade Federal do Paraná - UFPR Av. Prefeito Lothário Meissner, 632. Campus III. Curitiba/PR E-mail: rdcolauto@ufpr.br
\end{abstract}

\section{RESUMO}

As informações evidenciadas sobre as atividades logísticas denotam ser preteridas em detrimento de informações de caráter obrigatório. O modelo World Class Logistics propõe o monitoramento do desempenho logístico das companhias com o enfoque em quatro competências: Posicionamento, Integração, Agilidade e Mensuração. A Competência Mensuração se preocupa em mostrar indicadores de (1) Custo; (2) Serviço ao Cliente e Qualidade; (3) Produtividade; e (4) Gerenciamento de Ativos. Entende-se que 0 modelo possibilita 0 monitoramento por meio de algumas informações financeiras divulgadas pelas companhias de capital aberto. Nesse contexto, sugere-se a seguinte questão de pesquisa: qual o desempenho logístico de produtividade de companhias brasileiras com ações negociadas na Bolsa de Nova lorque na perspectiva do modelo World Class Logistics? A amostra foi composta por quinze empresas do setor de produção e comércio e para análise dos dados utilizou-se 
Desempenho Logístico de Produtividade em Companhias Brasileiras Listadas na Bolsa de Nova lorque na Perspectiva do Modelo World Class Logistics Helton Cristian de Paula, Joyce Menezes da Fonseca Tonin, Ramon Kael Benassi Bachmann, Romualdo

estatística descritiva segmentada em clusters. Os resultados mostram que as empresas Braskem, CBD, Perdigão, Sadia e Ultrapar, que compuseram o cluster 1, não obtiveram bom desempenho nos Indicadores Logísticos de Produtividade de forma geral. As empresas Ambev, Aracruz, CSN, Cosan, Embraer, Gafisa, Gerdau e VCPA, que formam o cluster 2, se destacaram nos indicadores Despesas Operacionais versus Mercadorias Despachadas e Output Total. O cluster 3, composto pelas empresas Petrobras e Vale, foi o que apresentou melhor desempenho geral nos Indicadores Logísticos de Produtividade. Isso ocorreu devido ao crescimento do Lucro Operacional ter superado o resultado inferior nos outros dois indicadores.

Palavras-chave: Desempenho de Produtividade. Modelo World Class Logistics. Avaliação de Desempenho.

\section{Productivity Logistics Performance of Brazilian Companies Listed on Stock Exchange of New York Under the World Class Logistics Model Perspective}

\section{ABSTRACT}

The disclosed information about the logistical activities seem to be set aside at the expense of mandatory information. The World Class Logistics model proposes the logistical performance monitoring of companies focusing four competences: Positioning, Integration, Agility and Measuring. The Measuring competence seeks to show ratios of (1) Cost, (2) Customer Service and Quality, (3) Productivity and (4) Asset Management. It is understood that the model enables the monitoring through some disclosed financial information by public companies. In this context, it is suggested the following research question: what is the Productivity Logistical Performance of Brazilian companies with shares traded on the New York Stock Exchange under the World Class Logistics model perspective? The sample was composed of fifteen production and trade sectors companies and for data analysis, descriptive statistics segmented in clusters was used. The results show that the companies Braskem, CBD, Perdigao, Sadia and Ultrapar, which composed the cluster 1, did not obtain good performance in Productivity Logistical indicators in general. The companies Ambev, Aracruz, CSN, Cosan, Embraer, Gafisa, Gerdau and VCPA, which formed the cluster 2, have been highlighted in Operational Outlay versus Dispatched Goods and Total Output ratios. The cluster 3, composed of the companies Petrobras and Vale, expressed the best general performance in Logistical Productivity ratios. This happened because the Operational Profit growth has overcome the inferior results of the other ratios.

Keywords: Productivity Performance. World Class Logistics Model. Performance Evaluation. 
Desempenho Logístico de Produtividade em Companhias Brasileiras Listadas na Bolsa de Nova

Iorque na Perspectiva do Modelo World Class Logistics

Helton Cristian de Paula, Joyce Menezes da Fonseca Tonin, Ramon Kael Benassi Bachmann, Romualdo

Douglas Colauto

\section{INTRODUÇÃO}

Bowersox e Closs (2001) afirmam que os gastos com logística são relevantes e chegam a representar de 5 a $35 \%$ do valor das vendas, variando de acordo com o tipo de atividade, da operação e da relação peso/valor dos produtos e materiais. Nos EUA os valores consumidos com atividades logísticas representam $10 \%$ do Produto Interno Bruto (PIB) do país, enquanto no mundo estima-se que os gastos com a atividade alcancem até $20 \%$ do PIB mundial (FRANZELLE, 2001). Para Costa et al. (2002), no Brasil, o valor total despendido com logística é superior ao PIB de países como Chile, Bolívia e Portugal.

A fim de atender aos acionistas e clientes, a logística busca realizar o gerenciamento dos processos de suprimento, produção e distribuição. Tais atividades requerem investimentos em ferramentas para coordenar esses fluxos de atividades e avaliar o desempenho da organização como um todo. Um grupo de pesquisadores em Logística da Michigan State University, denominado Global Logistics Research Team (GLRT) apresentou, em 1995, um modelo para avaliação do desempenho logístico intitulado World Class Logistics Model - Modelo de Logística de Classe Mundial para capturar a performance logística das empresas. O modelo prevê o monitoramento da logística nas quatro competências: (1) Posicionamento, (2) Integração, (3) Agilidade e (4) Mensuração.

Para monitorar o desempenho das três primeiras competências, Posicionamento, (2) Integração e (3) Agilidade é preciso conhecer o planejamento estratégico das empresas e ter acesso a dados gerenciais, os quais não são divulgados aos usuários externos de informações financeiras. Com relação à competência Mensuração, o conjunto de indicadores sugeridos pelos autores Bowersox et al. (1989), Stock e Lambert (2001), Mentzer et al. (1996), Fleury e Lavalle (1997), Stainer (1997), Franzelle (2001), Bowersox e Closs (2001) para o modelo World Class Logistics denotam possibilidade de verificação empírica, dado a possibilidade de divulgação nos relatórios financeiros das companhias, em especial daquelas de capital aberto. Desse 
Desempenho Logístico de Produtividade em Companhias Brasileiras Listadas na Bolsa de Nova lorque na Perspectiva do Modelo World Class Logistics Helton Cristian de Paula, Joyce Menezes da Fonseca Tonin, Ramon Kael Benassi Bachmann, Romualdo

modo, optou-se por centrar esta pesquisa na competência Mensuração do modelo World Class Logistics.

As sugestões métricas de desempenho para monitorar a competência Mensuração, segundo o GLRT (1995), possibilita contemplar um número expressivo de indicadores, porém o monitoramento de todos eles pode comprometer a relação custo/benefício das empresas, além do fato de alguns indicadores não serem facilmente aplicáveis na maior parte das empresas. Portanto, a contribuição desta pesquisa consiste em apresentar um conjunto enxuto de indicadores para avaliação do desempenho logístico de produtividade, enquadrado na competência Mensuração. Nesse contexto apresenta-se a seguinte questão de pesquisa: qual o desempenho logístico de produtividade de companhias brasileiras com ações negociadas na Bolsa de Nova lorque na perspectiva do modelo World Class Logistics? Assim, o objetivo geral da pesquisa é apresentar a evolução do desempenho logístico de produtividade em companhias brasileiras com ações negociadas na Bolsa de Nova lorque no período de 2004 a 2008, na concepção do modelo World Class Logistics.

\section{MODELO WORLD CLASS LOGISTICS PARA MENSURAÇÃO DE DESEMPENHO}

O modelo de mensuração do desempenho logístico foi elaborado por pesquisadores do The Global Logistics Research Team (GLRT) da Michigan State University, que promovem, desde 1986, uma série de pesquisas com o objetivo de estudar fatores que determinam ou influenciam a qualidade da prática logística. A primeira pesquisa realizada pelo GLRT (1995) teve como foco principal entender o que constituía a melhor prática na então emergente disciplina da logística. A pesquisa culminou na publicação do livro Leading Edge Logistics em 1989. Um dos resultados da pesquisa foi o desenvolvimento de um modelo denominado The Leading Edge Best Practice. A segunda pesquisa realizada pelo GLRT (1995) foi publicada em 1992. O objetivo era fundir as capacitações gerais das empresas líderes em performance logística em um modelo relacional que poderia servir aos gerentes como um guia na 
Desempenho Logístico de Produtividade em Companhias Brasileiras Listadas na Bolsa de Nova Iorque na Perspectiva do Modelo World Class Logistics Helton Cristian de Paula, Joyce Menezes da Fonseca Tonin, Ramon Kael Benassi Bachmann, Romualdo

renovação da logística. Os resultados foram publicados com o título de Logistical Excellence: it's not business as usual.

Outra pesquisa do GLRT, publicada em 1995 com a denominação World Class Logistics: the challenge of managing continuous change, teve quatro objetivos básicos: (1) compreender aspectos fundamentais da performance logística superior; (2) verificar se esta melhor prática poderia ser generalizada por meio das fronteiras nacionais e ambientes culturais; (3) entender como os gerentes implementam com sucesso mudanças de alto impacto; e (4) desenvolver evidência factual e circunstancial para dar suporte à discussão acerca da relevância de se ter uma logística de classe mundial. Os resultados geraram o modelo World Class Logistics, que substituiu o The Leading Edge Best Practice. O modelo World Class Logistics, concebido a partir da investigação das melhores práticas logísticas, apresenta os indicadores utilizados pelas empresas com reconhecida excelência na mensuração do desempenho logístico, também conhecidas como empresas com logística de classe mundial.

De acordo com o GLRT (1995), o modelo World Class Logistics é composto por quatro competências que devem ser observadas pelas empresas para avaliação da performance logística: (a) Posicionamento; (b) Integração; (c) Agilidade; e (d) Mensuração. Os pesquisadores do GLRT (1995) propuseram ainda que para se ter um desempenho logístico aderente ao conceito de Logística de Classe Mundial as empresas devem apresentar desempenho simultâneo e consistente nas quatro competências básicas.

O GLRT (1995) defende que o Posicionamento refere-se à forma como a empresa compete, o tipo de serviço ofertado, o grupo de consumidores alvo e a comparação com a oferta dos concorrentes. A segunda competência, Integração, é lida com o porte operacional de uma operação logística de excelência e objetiva satisfazer o cliente. A terceira competência, Agilidade, relaciona-se à competitividade da empresa. A quarta competência, Mensuração, mede e avalia o desempenho logístico a fim de melhorá-lo, pois a medição proporciona base para a realização de ajustes nas demais competências logísticas. As quatro competências são fundamentais para o alcance do status de nível mundial. No entanto, em pesquisas do GLRT (1995) não foram 
Desempenho Logístico de Produtividade em Companhias Brasileiras Listadas na Bolsa de Nova lorque na Perspectiva do Modelo World Class Logistics Helton Cristian de Paula, Joyce Menezes da Fonseca Tonin, Ramon Kael Benassi Bachmann, Romualdo

identificadas dentre as empresas pesquisadas uma que tenha se destacado nas quatro capacidades ao mesmo tempo.

\section{MÉTRICAS DO WORLD CLASS LOGISTICS PARA DESEMPENHO NA PRODUTIVIDADE}

Stainer (1997) afirma que controlar a performance logística é uma das principais preocupações dos gerentes, principalmente devido às constantes mudanças no ambiente competitivo e à ocorrência de eventos imprevisíveis que podem afetar os níveis estimados de performance. Bowersox e Closs (2001) acreditam que apenas por meio da mensuração do desempenho é possível avaliar se as operações logísticas estão atingindo as metas de serviços desejadas. Pesquisas do GLRT (1995) evidenciaram que organizações com logística de classe mundial compreendem a medição de desempenho como uma competência crítica e mostram maior proficiência em relação aos seus competidores na mesma.

Chow et al. (1994) afirmam que a definição de indicadores de desempenho não é uma tarefa fácil, uma vez que a performance deve ser avaliada sob diversas dimensões. Assim, um sistema de indicadores deve ser composto por um grupo de medidas que capturem, se não todas, as dimensões mais importantes que forneçam aos gerentes uma visão tanto de curto como de longo prazo do desempenho da empresa. Slack e Lewis (2003) complementam que o sistema de indicadores deve ser capaz de refletir os principais objetivos de performance da companhia.

Para Mentzer e Firman (1994) a decisão do que incluir na medição do desempenho sugere cautela no momento da escolha, pois o custo marginal para a obtenção de uma informação pode ser superior ao seu benefício. Bowersox et al. (1989) mostram que na pesquisa Leading Edge Logistics: competitive positioning for the 1990's as medidas de desempenho empregadas pelas empresas de classe mundial pertencem às seguintes áreas: (1) Custo; (2) Serviço ao Cliente e Qualidade; (3) Produtividade; e (4) Gerenciamento de Ativos. 
Desempenho Logístico de Produtividade em Companhias Brasileiras Listadas na Bolsa de Nova lorque na Perspectiva do Modelo World Class Logistics Helton Cristian de Paula, Joyce Menezes da Fonseca Tonin, Ramon Kael Benassi Bachmann, Romualdo Douglas Colauto

O GLRT (1995) identificou as mesmas medidas de desempenho que Bowersox et al. (1989), acrescentando que as empresas em geral mensuram com maior frequência o desempenho nas dimensões custo e serviço ao cliente e as firmas com performance logística de classe mundial avaliam além destas duas, as dimensões de qualidade, produtividade e gerenciamento de ativos.

Stainer (1997) defende que as medidas de produtividade são o tipo mais comum e intuitivo de indicadores utilizados, além de serem importantes no controle e análise da performance logística, devendo fazer parte do grupo de métricas de performance deste tipo de sistema. Para Bowersox et al. (1989) a mensuração de produtividade se torna simples quando um sistema possui outputs claramente mensuráveis e identificáveis e inputs que podem ser relacionados aos outputs. Porém, argumentam que na prática a medição da produtividade poderá ser frustrante quando for difícil isolar os múltiplos outputs ou determinar como eles devem ser combinados, já que o output nem sempre é óbvio ou fácil de mensurar.

No Quadro 1 apresentam-se exemplos de medidas de mensuração do desempenho logístico de produtividade, o respectivo pesquisador e 0 ano de publicação.

\begin{tabular}{|c|c|c|}
\hline Indicadores & Autores & Ano \\
\hline Produtividade da mão de obra do armazém & CLM & 1995 \\
\hline Unidades expedidas por funcionário & CLM e Bowersox e Closs & 1995 e \\
& & 2001 \\
\hline Unidades por unidade monetária de mão de obra & CLM e Bowersox e Closs & 1995 e \\
& & 2001 \\
\hline Produtividade da mão-de-obra no transporte & CLM & 1995 \\
\hline Ociosidade do equipamento & CLM & 1995 \\
\hline $\begin{array}{c}\text { Número de pedidos por representante de vendas } \\
\text { Despesas operacionais versus mercadorias } \\
\text { processadas }\end{array}$ & Bowersox e Closs & 1995 e Bowersox e Closs \\
2001 \\
\hline $\begin{array}{c}\text { Despesas operacionais versus mercadorias } \\
\text { recebidas ou despachadas }\end{array}$ & Bowersox e Closs & 2001 \\
\hline $\begin{array}{c}\text { Receita de Vendas menos Valor consumido na } \\
\text { operação }\end{array}$ & Stainer & 2001 \\
\hline Output total & Stainer & 1997 \\
\hline
\end{tabular}

Quadro 1 - Medidas de Mensuração de Desempenho Logístico de Produtividade Fonte: Adaptado de GERVÁSIO, M. H.; HIIJAR, M. F.; FIGUEIREDO, K. F. (2005). 
Desempenho Logístico de Produtividade em Companhias Brasileiras Listadas na Bolsa de Nova Iorque na Perspectiva do Modelo World Class Logistics Helton Cristian de Paula, Joyce Menezes da Fonseca Tonin, Ramon Kael Benassi Bachmann, Romualdo

Stainer (1997) pondera que existem três tipos de medidas de produtividade. O primeiro tipo é denominado medida parcial. Expressa a relação entre determinado output e um único input, tal como mão-de-obra ou capital empregado. Este indicador é útil quando a medição for concentrada em um único input, mantendo-se os demais constantes. O segundo tipo de medida de produtividade, value added productivity, é definido como a receita de vendas deduzida do valor consumido na operação com matéria-prima, serviços etc. O terceiro tipo envolve indicadores de produtividade total e representam a relação entre o output total e o input total.

Para Bowersox e Closs (2001) a produtividade também pode ser medida tanto no nível macro quanto no micro. A medição no nível macro se refere a indicadores de tendência de performance para o total das instalações das operações de um grupo. Entre estas medidas pode ser citada a razão entre o total das despesas operacionais e o total das mercadorias processadas, ou valor total das mercadorias recebidas, ou mesmo o valor total das mercadorias despachadas. No nível micro, as métricas estão relacionadas diretamente a certa operação: número de paletes movimentados por hora; número de unidades separadas ou empacotadas por hora; quantidade de pedidos processados por hora, entre outras.

Quanto à competência Mensuração, o modelo World Class Logistics contempla a medição de desempenho em quatro perspectivas distintas: desempenho de serviço ao cliente; custos; produtividade e gerenciamento de ativos. Bowersox et al. (1986), Lambert e Stock (1992), Mentzer et al. (1996), Fleury e Lavalle (2000), Stainer (1997), Franzelle (2001), Bowersox e Closs (2001), propuseram indicadores para mapear a perspectiva de produtividade. No entanto, muitos indicadores são difíceis de serem operacionalizados, seja pelo fato das informações serem de caráter eminentemente gerencial, seja porque sua aplicação pode comprometer a relação custo-benefício. O IMAM - Inovação e Melhoramento na Administração Moderna (2003) apresentou uma reorganização dos quatro grupos de indicadores de desempenho da competência Mensuração contemplados no modelo World Class Logistics. Nessa perspectiva, os indicadores foram reagrupados em dois grandes grupos: (1) Indicadores de Eficácia; e (2) Indicadores de Eficiência. Comparando-se a abordagem do IMAM (2003) com a do 
Desempenho Logístico de Produtividade em Companhias Brasileiras Listadas na Bolsa de Nova lorque na Perspectiva do Modelo World Class Logistics Helton Cristian de Paula, Joyce Menezes da Fonseca Tonin, Ramon Kael Benassi Bachmann, Romualdo

GLRT (1995), verifica-se que os indicadores classificados no subgrupo Foco Interno são muito semelhantes àqueles propostos na mensuração do desempenho de serviço ao cliente. Em resumo, os indicadores de eficácia são muito convergentes com os apresentados para mensurar o desempenho de Serviço ao Cliente. Os indicadores para avaliar a eficiência são aderentes aos propostos para mensurar o desempenho de Custos, Produtividade e Gerenciamento de Ativos.

A mudança substancial sugerida pelo IMAM (2003) atém-se exclusivamente à realocação dos indicadores de custos, produtividade e gerenciamento de ativos para o Grupo de Indicadores de Eficiência, classificando-os em Custos, Produtividade e Utilização de Recursos. Desse modo, este estudo utiliza a perspectiva da produtividade, conforme abordagem do GLRT (1995), com indicadores classificados no Grupo de Indicadores de Eficiência, conforme proposta do IMAM (2003).

Faria e Costa (2005) alertam para um grande desafio existente no processo de mensuração de desempenho logístico: a limitação do número de indicadores a serem utilizados. Andel (1997) afirma que há um impacto dual na elaboração dos relatórios: por um lado, existe um aumento nos custos com a preparação de relatórios, controles, sistemas de informações, etc. e, por outro, os controles podem acompanhar todo o fluxo sincronizado de materiais e processos, visando minimizar ou eliminar os desperdícios e atividades que não agregam valor. Portanto, é prudente selecionar alguns indicadores de eficiência que possam ser verificados periodicamente e, que possam ao mesmo tempo, mostrar de forma ampla a performance das atividades logísticas de produtividade.

Nessa perspectiva, dentre os indicadores sugeridos para mensuração do desempenho logístico de Produtividade, apresentados no Quadro 1, selecionou-se seis que podem ser levantados a partir de informações publicadas. O critério de seleção do indicador foi a possibilidade de verificação empírica em informações disponibilizadas aos usuários externos. No Quadro 2 apresentam-se os indicadores selecionados, bem como a fórmula para cálculo e a fonte de dados para verificação de cada um deles. 
Desempenho Logístico de Produtividade em Companhias Brasileiras Listadas na Bolsa de Nova lorque na Perspectiva do Modelo World Class Logistics Helton Cristian de Paula, Joyce Menezes da Fonseca Tonin, Ramon Kael Benassi Bachmann, Romualdo Douglas Colauto

\begin{tabular}{|c|c|c|}
\hline \multicolumn{3}{|c|}{ DESEMPENHO POR PRODUTIVIDADE } \\
\hline Indicadores & Fórmulas & Fonte de Dados \\
\hline $\begin{array}{c}\text { 1-Despesas Operacionais versus } \\
\text { mercadorias processadas }\end{array}$ & $\begin{array}{c}\text { Total das despesas operacionais/ } \\
\text { mercadorias processadas (a) }\end{array}$ & $\begin{array}{l}\text { DRE. Relatório 20F } \\
\text { e Relatório de } \\
\text { Administração }\end{array}$ \\
\hline $\begin{array}{l}\text { 2-Despesas Operacionais versus } \\
\text { mercadorias recebidas ou } \\
\text { despachados }\end{array}$ & $\begin{array}{l}\text { Total de despesas operacionais } \\
\text { mercadorias despachadas }\end{array}$ & $\begin{array}{l}\text { DRE. Relatório 20F } \\
\text { e Relatório de } \\
\text { Administração }\end{array}$ \\
\hline 3-Lucro operacional & $\begin{array}{l}\text { Receitas de vendas- valor consumido na } \\
\text { operação }\end{array}$ & DRE \\
\hline $\begin{array}{l}\text { 4-Unidades Expedidas por } \\
\text { funcionários }\end{array}$ & $\begin{array}{l}\text { Quantidade de unidades expedidas/ } \\
\text { quantidade de funcionário da empresa }\end{array}$ & $\begin{array}{l}\text { Relatório } 20 \mathrm{~F} \mathrm{e} \\
\text { Relatório de } \\
\text { Administração }\end{array}$ \\
\hline 5-Ociosidade do equipamento & $\begin{array}{l}\text { Capacidade instalada/ quantidade } \\
\text { processada (b) }\end{array}$ & $\begin{array}{l}\text { Relatório } 20 \mathrm{~F} \mathrm{e} \\
\text { Relatório de } \\
\text { Administração }\end{array}$ \\
\hline 6-Output Total & $\begin{array}{l}\text { Somatório de todos os custos de } \\
\text { insumos, incluindo mercadorias, mão-de- } \\
\text { obra e depreciação. }\end{array}$ & DRE \\
\hline $\begin{array}{l}\text { Observação: } \\
\text { a) As mercadorias processad } \\
\text { acabados mais total unitário de } \\
\text { b) Ociosidade do equipamento pa }\end{array}$ & $\begin{array}{l}\text { as são obtidas pelo (estoque inicial em unid } \\
\text { produtos acabados expedidos menos estoc } \\
\text { produtos acabados) } \\
\text { ara cálculo da quantidade processada suger } \\
\text { descritivo no item anterior (a) }\end{array}$ & $\begin{array}{l}\text { lades de produtos } \\
\text { que unitário final de } \\
\text { e-se utilizar o cálculo }\end{array}$ \\
\hline
\end{tabular}

Quadro 2 - Delineamento de Indicadores de Eficiência para Mensuração do Desempenho Logístico de Produtividade

Fonte: elaborado pelos autores.

Para o grupo de desempenho logístico de Produtividade, selecionaram-se os seguintes indicadores: (1) Despesas operacionais versus mercadorias processadas; (2) Despesas operacionais versus mercadorias recebidas ou despachadas; (3) Lucro Operacional; (4) Unidades expedidas por funcionário; (5) Ociosidade do equipamento; e (6) Output total.

O indicador Despesas operacionais versus mercadorias processadas mede a capacidade produtiva utilizada pela empresa e os recursos gastos nesse processo. As Despesas Operacionais versus Mercadorias Recebidas ou Despachadas avalia o atendimento de pedidos de clientes ou recebimento de materiais e os recursos gastos 
Desempenho Logístico de Produtividade em Companhias Brasileiras Listadas na Bolsa de Nova lorque na Perspectiva do Modelo World Class Logistics Helton Cristian de Paula, Joyce Menezes da Fonseca Tonin, Ramon Kael Benassi Bachmann, Romualdo

nos processos. O terceiro indicador, Lucro Operacional, mostra a eficiência na aquisição de insumos, produção e distribuição de mercadorias, funções coordenadas pelo setor de logística. As Unidades expedidas por funcionário proporcionam uma visão da produtividade da mão-de-obra necessária no processo e propicia informações que auxiliam na tomada de decisões de investimento e modernização de processos.

$\mathrm{O}$ indicador de Ociosidade do equipamento mede a capacidade instalada da empresa que não está sendo usada para produção. Fornece dados para tomar decisões relacionadas à produção, como aceitar um pedido extra; e financeiras, como fornecer um desconto no processo para incentivar pedidos, provocando aumento na produção e redução de custos associados à ociosidade. $O$ indicador Outputs totais captura o desempenho logístico na medida em que representa o custo de todos os fatores de produção, incluindo a depreciação, que representa o consumo dos bens de capitais no processo. Apresenta uma visão ampliada dos custos incorridos.

\section{METODOLOGIA}

Para avaliação do desempenho logístico de produtividade por meio de indicadores, utilizou-se a análise descritiva segmentada em conglomerados (Cluster analysis). Quanto à abordagem do problema, a pesquisa caracteriza-se como quantitativa. O estudo é longitudinal, pois os indicadores de desempenho logístico de produtividade são analisados no período de 2004 a 2008.

A população foi composta por companhias sediadas no Brasil, com ações negociadas na Bolsa de Valores de Nova lorque (NYSE). Portanto, as demonstrações contábeis dessas empresas foram elaboradas segundo os padrões de contabilidade norte-americanos - Usually General Accounting Accepts Principles - USGAAP. Assim, todas as informações em valores monetários estão reportadas em dólares americanos. Em Junho de 2009, eram negociadas na NYSE as ações de 37 (trinta e sete) companhias sediadas no Brasil.

Algumas empresas são listadas mais de uma vez, como é o caso da Vale e da Petrobras. Isso ocorre pela existência de dois tipos de ações: preferenciais e ordinárias. 
Desempenho Logístico de Produtividade em Companhias Brasileiras Listadas na Bolsa de Nova lorque na Perspectiva do Modelo World Class Logistics Helton Cristian de Paula, Joyce Menezes da Fonseca Tonin, Ramon Kael Benassi Bachmann, Romualdo

Além disso, existem as empresas de participações, como é o caso da Brasil Telecom Participações S.A., cujo objeto social é participar de outras companhias, o que reduz as possibilidades de avaliar o desempenho em logística.

Outra constatação é a variedade de setores de atuação das companhias. As características de alguns setores geram empecilhos para a avaliação do desempenho logístico, uma vez que setores de prestação de serviços como o bancário e o da aviação não avaliam seu desempenho por unidades, como ocorre no segmento industrial, o que prejudica a análise de indicadores de produtividade dentro da mensuração do desempenho logístico. A mesma situação ocorre com as concessionárias de serviços públicos que atuam no setor de energia, saneamento básico e telecomunicações. Tendo em vista estas observações, excluiu-se da população uma observação de cada companhia listada em duplicidade, pelos motivos citados no parágrafo anterior, além das empresas de participação, daquelas que atuam no segmento de serviço e das concessionárias de serviços públicos.

A amostra foi composta basicamente por empresas pertencentes ao setor de produção e restaram 15 companhias, representando $41 \%$ da população. As companhias selecionadas atuam em segmentos diversos, como mineração, petroquímico, etc. Considerando esta diversidade de segmentos de atuação e o número reduzido de empresas em cada segmento, não foi possível fazer a análise dos dados por área de atuação. Por isso, optou-se pela utilização do agrupamento hierárquico e não hierárquico de Clusters. Para a coleta dos dados utilizou-se a Demonstração do Resultado, o Balanço Patrimonial, Relatório de Administração e o Formulário 20F, referente ao período de 2004 a 2008. As demonstrações contábeis foram coletadas a partir do sítio da Bolsa de Valores de Nova lorque (NYSE). A coleta de dados foi complementada com informações disponíveis no software Economática®.

No processo de coleta de dados, diversas companhias da amostra não apresentavam três informações necessárias ao cálculo de alguns indicadores: (1) Estoque Unitário Inicial e Final de Produtos Acabados; (2) Quantidade de Funcionários, e; (3) Capacidade Instalada. A ausência destes dados inviabilizou o cálculo dos indicadores (1) Despesas Operacionais versus Mercadorias Processadas, (4) Unidades 
Desempenho Logístico de Produtividade em Companhias Brasileiras Listadas na Bolsa de Nova lorque na Perspectiva do Modelo World Class Logistics Helton Cristian de Paula, Joyce Menezes da Fonseca Tonin, Ramon Kael Benassi Bachmann, Romualdo

Expedidas por Funcionários e (5) Ociosidade do Equipamento. Para o cálculo do indicador (2) Despesas Operacionais versus Mercadorias Expedidas foi preciso encontrar a quantidade de mercadorias expedidas, e essa informação não é disponibilizada em nenhum reporte financeiro em USGAAP, justificando a utilização do Relatório de Administração, apresentado pelas empresas a Comissão de Valores Mobiliários (CVM), segundo os princípios contábeis brasileiros. Essa informação não prejudica a análise, pois o indicador é apresentado em unidade não monetária (toneladas, hectolitro, etc.).

Considerando essas constatações, foram utilizados na pesquisa três indicadores de desempenho logístico de produtividade, conforme apresentado no Quadro 3.

\begin{tabular}{|c|}
\hline DESEMPENHO EM PRODUTIVIDADE \\
\hline Despesas operacionais versus mercadorias recebidas ou despachadas \\
\hline Lucro Operacional \\
\hline Output total \\
\hline
\end{tabular}

Quadro 3 - Indicadores de Eficiência utilizados para Mensuração do Desempenho Logístico de Produtividade

Fonte: elaborado pelos autores.

Desse modo, o Desempenho Logístico de Produtividade foi representado por três indicadores. Apesar da redução dos indicadores, acredita-se que os remanescentes representam ainda um mérito, tendo em vista que os dados referentes à produtividade são eminentemente gerenciais e estratégicos para as companhias.

Os dados coletados foram tratados por meio da função Create Time Series, disponível no software SPSS $\AA$, versão 17.0. Esta função requer a utilização do método das médias móveis da série histórica, por meio do qual calcula-se a média móvel das cinco observações encontradas para cada indicador, sendo a primeira delas a base. Os resultados são submetidos ao mesmo procedimento até que reste somente uma 
Desempenho Logístico de Produtividade em Companhias Brasileiras Listadas na Bolsa de Nova lorque na Perspectiva do Modelo World Class Logistics Helton Cristian de Paula, Joyce Menezes da Fonseca Tonin, Ramon Kael Benassi Bachmann, Romualdo Douglas Colauto

observação que represente a evolução média dos indicadores ao longo dos cinco anos observados.

\section{DESCRIÇÃO DOS RESULTADOS}

Os valores das médias dos cinco anos obtidos para os Indicadores de Desempenho Logístico de Produtividade são apresentados na Tabela 1.

Tabela 1 - Indicadores de Desempenho Logístico de Produtividade

\begin{tabular}{|c|c|c|c|}
\hline EMPRESA & $\begin{array}{c}\text { DESPESAS } \\
\text { OPERACIONAIS } \\
\text { VERSUS } \\
\text { MERCADORIAS } \\
\text { DESPACHADAS }\end{array}$ & $\begin{array}{c}\text { LUCRO } \\
\text { OPERACIONAL }\end{array}$ & $\begin{array}{c}\text { OUTPUT } \\
\text { TOTAL }\end{array}$ \\
\hline AMBEV & $52.847,56$ & 4.749 .668 .400 & 21.087 .960 .200 \\
\hline ARACRUZ & 171,05 & 981.007 .200 & 2.674 .745 .600 \\
\hline BRASKEM & 268,03 & 1.527 .213 .200 & 16.188 .501 .400 \\
\hline CBD & $2.869,14$ & 499.119 .200 & 13.175 .957 .200 \\
\hline CSN & $280.311,34$ & 4.663 .944 .000 & 8.774 .788 .200 \\
\hline COSAN & 171,86 & 71.003 .200 & 1.768 .157 .600 \\
\hline EMBRAER & $9.819 .230,22$ & 944.071 .600 & 7.657 .989 .600 \\
\hline GAFISA & $151.513,17$ & 90.136 .000 & 682.120 .800 \\
\hline GERDAU & $151.089,79$ & 5.262 .514 .800 & 24.095 .141 .600 \\
\hline PERDIGÃO & $2.105 .764,16$ & 448.169 .800 & 5.942 .016 .200 \\
\hline PETROBRAS & $7.028 .458,53$ & 40.035 .882 .600 & 42.354 .696 .600 \\
\hline SADIA & 779,02 & 590.692 .200 & 7.014 .947 .000 \\
\hline ULTRAPAR & $555.805,70$ & 490.447 .600 & 11.848 .886 .000 \\
\hline VALE & $23.134,12$ & 20.502 .752 .400 & 24.312 .807 .400 \\
\hline VCPA & $442.291,69$ & 660.276 .600 & 2.496 .979 .800 \\
\hline
\end{tabular}

Fonte: elaborado pelos autores.

Analisando os resultados obtidos para os indicadores de Desempenho de Produtividade, calculados para cada uma das empresas da amostra por meio da função

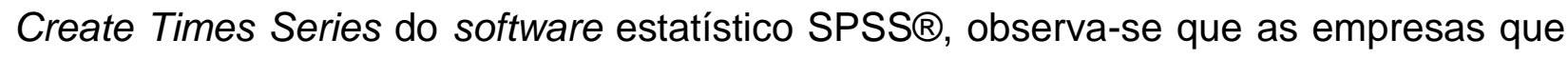
se destacam de forma geral nos indicadores são aquelas que têm maior porte ou 
Desempenho Logístico de Produtividade em Companhias Brasileiras Listadas na Bolsa de Nova lorque na Perspectiva do Modelo World Class Logistics Helton Cristian de Paula, Joyce Menezes da Fonseca Tonin, Ramon Kael Benassi Bachmann, Romualdo

trabalham com mercadorias com maior valor agregado. No primeiro indicador, despesas operacionais versus mercadorias despachadas, a empresa que se destacou foi a Embraer. Provavelmente isso ocorreu porque, embora ela venda e fature menor quantidade de mercadorias, pois comercializa jatos, como se trata de produtos com alto valor agregado e unitário, ela é a que apresenta o maior indicador. Nos indicadores de lucro operacional e output total o destaque foi a Petrobras e a Vale. Como tais empresas estão entre as maiores do país, é natural que apresentem os maiores números absolutos.

Conforme observado na Tabela 1, as variáveis não estão na mesma escala. Para eliminar o viés gerado pelas diferenças nas escalas das variáveis padronizaram-se os dados antes que as similaridades fossem calculadas. Esta padronização foi obtida pela conversão de cada variável em escores padrão (também conhecidos com Scores Z), que são calculados por meio da subtração da média e divisão pelo desvio-padrão para cada uma das variáveis. Esse processo converte cada escore de dados iniciais em um valor padronizado com uma média de 0 e um desvio-padrão de 1. Na Tabela 2 apresentam-se os Scores $Z$. 
Desempenho Logístico de Produtividade em Companhias Brasileiras Listadas na Bolsa de Nova lorque na Perspectiva do Modelo World Class Logistics Helton Cristian de Paula, Joyce Menezes da Fonseca Tonin, Ramon Kael Benassi Bachmann, Romualdo

Tabela 2 - Scores $Z$ - Indicadores de Desempenho Logístico de Produtividade

\begin{tabular}{|c|c|c|c|}
\hline EMPRESA & $\begin{array}{c}\text { DESPESAS } \\
\text { OPERACIONAIS } \\
\text { VERSUS } \\
\text { MERCADORIAS } \\
\text { DESPACHADAS }\end{array}$ & $\begin{array}{c}\text { LUCRO } \\
\text { OPERACIONAL }\end{array}$ & $\begin{array}{c}\text { OUTPUT } \\
\text { TOTAL }\end{array}$ \\
\hline AMBEV & $-0,49$ & $-0,09$ & $-0,02$ \\
\hline ARACRUZ & $-0,52$ & $-0,47$ & $-0,50$ \\
\hline BRASKEM & $-0,52$ & $-0,43$ & $-0,14$ \\
\hline CBD & $-0,52$ & $-0,46$ & $-0,23$ \\
\hline CSN & $-0,35$ & 0,18 & $-0,34$ \\
\hline COSAN & $-0,52$ & $-0,54$ & $-0,51$ \\
\hline EMBRAER & 2,21 & $-0,43$ & $-0,37$ \\
\hline GAFISA & $-0,48$ & $-0,50$ & $-0,54$ \\
\hline GERDAU & $-0,44$ & 0,07 & 0,19 \\
\hline PERDIGAO & 0,61 & $-0,48$ & $-0,35$ \\
\hline PETROBRAS & 2,50 & 3,09 & 3,51 \\
\hline SADIA & $-0,52$ & $-0,46$ & $-0,36$ \\
\hline ULTRAPAR & $-0,14$ & $-0,46$ & 0,01 \\
\hline VALE & $-0,50$ & 1,47 & 0,16 \\
\hline VCPA & $-0,34$ & $-0,49$ & $-0,51$ \\
\hline
\end{tabular}

Fonte: elaborado pelos autores.

Desse modo, com os dados padronizados apresentados na Tabela 2 foram calculados os agrupamentos hierárquicos e não hierárquicos, também conhecidos como conglomerados. Foram feitas simulações testando a possibilidade de composição de 5 Clusters. Para identificar o melhor agrupamento, foram analisados os coeficientes de agrupamento (aglomeração) apresentados na Tabela 3:

Tabela 3 - Coeficientes de Aglomeração para definir o Número de Clusters

\begin{tabular}{|c|c|c|}
\hline Número de Clusters & Coeficiente de Aglomeração & Variação do Coeficiente \\
\hline 5 & 7,5789 & $43,52 \%$ \\
\hline 4 & 4,2807 & $36,45 \%$ \\
\hline $\mathbf{3}$ & $\mathbf{2 , 7 2 0 3}$ & $\mathbf{5 1 , 9 6 \%}$ \\
\hline $\mathbf{2}$ & $\mathbf{1 , 3 0 6 9}$ & $\mathbf{7 9 , 4 4 \%}$ \\
\hline 1 & 0,2686 & \\
\hline
\end{tabular}

Fonte: elaborado pelos autores.

Por meio da análise da Tabela 3, observa-se que a maior variação percentual ocorre de dois para três clusters (quase 28\%). Nas demais proposições de 
Desempenho Logístico de Produtividade em Companhias Brasileiras Listadas na Bolsa de Nova lorque na Perspectiva do Modelo World Class Logistics Helton Cristian de Paula, Joyce Menezes da Fonseca Tonin, Ramon Kael Benassi Bachmann, Romualdo

agrupamento, a variação é bem menor, sendo de cerca de $15 \%$ de três para quatro agrupamentos e de cerca de $7 \%$ de quatro para cinco agrupamentos. Esse percentual de mudança do coeficiente de aglomeração auxilia na identificação dos aumentos relativos à heterogeneidade do cluster. Com base nestes percentuais definiu-se o uso de 3 conglomerados. Para realizar a análise dos Clusters foi utilizado o agrupamento hierárquico, calculando a Distância Euclidiana Quadrada em conjunto com o Método Ward. Tais técnicas foram definidas a partir das características da amostra. Segundo Hair (2005), o Método Ward tende a combinar agrupamentos com um pequeno número de observações e produzir agregados com aproximadamente o mesmo número de observações. Complementa afirmando que a Distância Euclidiana Quadrada é a distância recomendada para os métodos de agrupamento centroide e Ward.

Com o auxílio do software estatístico SPSS $\AA^{\circ}$, foi processada a análise dos dados das quinze companhias que compuseram a amostra final utilizando a Distância Euclidiana Quadrada e o Método de Aglomeração Ward. Os resultados são apresentados nas Tabelas 4 e 5.

Tabela 4 - Centro Inicial dos Clusters por indicador de desempenho logístico de produtividade

\begin{tabular}{|c|c|c|c|}
\hline Centro Inicial dos Clusters & Cluster1 & Cluster2 & Cluster 3 \\
\hline $\begin{array}{c}\text { Despesas Operacionais versus } \\
\text { Mercadorias Despachadas }\end{array}$ & $-0,14$ & $-0,48$ & 2,50 \\
\hline Lucro Operacional & $-0,46$ & $-0,50$ & 3,09 \\
\hline Output Total & 0,01 & $-0,54$ & 3,51 \\
\hline
\end{tabular}

Fonte: elaborado pelos autores.

A Tabela 4 apresenta os centros inicias de cada cluster, calculado para cada um dos indicadores. Na Tabela 5 são apresentados os centros finais dos clusters. 
Desempenho Logístico de Produtividade em Companhias Brasileiras Listadas na Bolsa de Nova lorque na Perspectiva do Modelo World Class Logistics Helton Cristian de Paula, Joyce Menezes da Fonseca Tonin, Ramon Kael Benassi Bachmann, Romualdo

Tabela 5 - Centro Final dos Clusters por indicador de desempenho logístico de produtividade

\begin{tabular}{|c|c|c|c|}
\hline Centro Final dos Clusters & Cluster1 & Cluster2 & Cluster3 \\
\hline $\begin{array}{c}\text { Despesas Operacionais versus } \\
\text { Mercadorias Despachadas }\end{array}$ & $-0,22$ & $-0,12$ & 1,00 \\
\hline Lucro Operacional & $-0,46$ & $-0,28$ & 2,28 \\
\hline Output Total & $-0,21$ & $-0,33$ & 1,83 \\
\hline
\end{tabular}

Fonte: elaborado pelos autores

A análise dos centros iniciais e finais de cada um dos indicadores permite a comparação dos resultados obtidos pelos clusters. Apesar da técnica de agrupamento em Clusters permitir a formação de grupos de empresas em função dos indicadores observados, viabilizando a comparação da performance entre os clusters, tal ferramenta não permite a análise individualizada de cada uma das companhias componentes da amostra, que é um dos objetivos dessa pesquisa. Por esse motivo, optou-se por realizar a análise descritiva dos dados segmentados em clusters.

Para analisar a evolução dos indicadores no período utiliza-se média móvel. Para obtenção da média móvel, os dados referentes ao ano de 2004 foram tomados como base para cálculo da variação do ano de 2005; os dados de 2005 para mostrar a variação de 2006, e assim sucessivamente. Todos esses valores foram convertidos em termos percentuais. Pode-se identificar a variação e a evolução dos indicadores de desempenho logístico ao longo da série histórica de cinco anos. A fim de facilitar a compreensão e análise dos resultados, as empresas são apresentadas de acordo com o agrupamento dos Clusters.

$\mathrm{Na}$ Tabela 6 apresentam-se as médias móveis dos indicadores de desempenho logístico de produtividade das empresas que compuseram o Cluster 1 para análise descritiva dos dados segmentados em clusters. 
Desempenho Logístico de Produtividade em Companhias Brasileiras Listadas na Bolsa de Nova lorque na Perspectiva do Modelo World Class Logistics Helton Cristian de Paula, Joyce Menezes da Fonseca Tonin, Ramon Kael Benassi Bachmann, Romualdo Douglas Colauto

Tabela 6 - Indicadores de Desempenho Logístico de Produtividade - Cluster 1

\begin{tabular}{|c|c|c|c|c|}
\hline BRASKEM & $2004 / 2005$ & $2005 / 2006$ & $2006 / 2007$ & $2007 / 2008$ \\
\hline $\begin{array}{c}\text { DESPESAS OPERACIONAIS VERSUS MERCADORIAS } \\
\text { DESPACHADAS }\end{array}$ & 6,02 & $(36,02)$ & 26,67 & $(1,38)$ \\
\hline LUCRO OPERACIONAL & $(25,74)$ & $(34,09)$ & 57,32 & $(27,73)$ \\
\hline OUTPUT TOTAL & 11,60 & 0,10 & 34,02 & 5,08 \\
\hline CBC & $2004 / 2005$ & $2005 / 2006$ & $2006 / 2007$ & $2007 / 2008$ \\
\hline $\begin{array}{c}\text { DESPESAS OPERACIONAIS VERSUS MERCADORIAS } \\
\text { DESPACHADAS }\end{array}$ & 4,28 & 1,44 & $(5,84)$ & 7,20 \\
\hline LUCRO OPERACIONAL & $(2,56)$ & $(29,65)$ & 40,42 & 48,70 \\
\hline OUTPUTTOTAL & 4,49 & 3,27 & 7,35 & 19,60 \\
\hline PERDIGÃO & $2004 / 2005$ & $2005 / 2006$ & $2006 / 2007$ & $2007 / 2008$ \\
\hline $\begin{array}{c}\text { DESPESAS OPERACIONAIS VERSUS MERCADORIAS } \\
\text { DESPACHADAS }\end{array}$ & 0,77 & 18,76 & 5,10 & 17,70 \\
\hline LUCRO OPERACIONAL & 10,20 & $(61,02)$ & 142,60 & $(2,72)$ \\
\hline OUTPUT TOTAL & 4,69 & 7,88 & 24,22 & 75,86 \\
\hline SADIA & 2004/2005 & $2005 / 2006$ & $2006 / 2007$ & $2007 / 2008$ \\
\hline $\begin{array}{c}\text { DESPESAS OPERACIONAIS VERSUS MERCADORIAS } \\
\text { DESPACHADAS }\end{array}$ & $(10,18)$ & 0,82 & 3,30 & 7,63 \\
\hline LUCRO OPERACIONAL & 6,50 & $(46,36)$ & 94,83 & 4,13 \\
\hline OUTPUT TOTAL & 17,06 & $(1,13)$ & 20,55 & 27,08 \\
\hline ULTRAPAR & 2004/2005 & $2005 / 2006$ & 2006/2007 & $2007 / 2008$ \\
\hline $\begin{array}{c}\text { DESPESAS OPERACIONAIS VERSUS MERCADORIAS } \\
\text { DESPACHADAS }\end{array}$ & 0,41 & 8,75 & 98,54 & 14,34 \\
\hline LUCRO OPERACIONAL & $(36,46)$ & $(7,80)$ & 47,15 & 46,74 \\
\hline OUTPUTTOTAL & 2,69 & 1,13 & 345,65 & 43,23 \\
\hline
\end{tabular}

Fonte: elaborado pelos autores.

As Despesas Operacionais da Braskem revelaram seguidas oscilações, apresentando aumento no biênio 2004/2005, seguido de retração, novo aumento em 2006/2007 e nova retração no biênio seguinte. A CBD apresentou estabilidade, com variações inferiores a 7,5\%. A Perdigão e a Ultrapar apresentaram aumento das Despesas em todo o período analisado, com destaque para o biênio 2006/2007, no qual o indicador da Ultrapar praticamente dobrou. O Lucro Operacional oscilou em todas as companhias. A Braskem apresentou retração deste indicador nos dois primeiros períodos, e apesar da evolução observada no período seguinte, fechou a série histórica com nova retração. A CBD e a Ultrapar iniciaram o período analisado com duas 
Desempenho Logístico de Produtividade em Companhias Brasileiras Listadas na Bolsa de Nova lorque na Perspectiva do Modelo World Class Logistics Helton Cristian de Paula, Joyce Menezes da Fonseca Tonin, Ramon Kael Benassi Bachmann, Romualdo

retrações, porém demonstraram alta nos dois períodos subsequentes. A Sadia e a Perdigão reportaram avanço no biênio 2004/2005, seguido de retração no período seguinte. Porém o biênio 2006/2007 apresentou a melhor performance das duas companhias, com aumento de $94 \%$ do Lucro Operacional da Sadia e de $142 \%$ da Perdigão. O Output Total registrou aumento em todos os períodos de todas as empresas. O destaque é o resultado da Braskem, que no biênio 2006/2007 registrou aumento de $345 \%$. Os gráficos dos períodos são apresentados no Quadro 4.

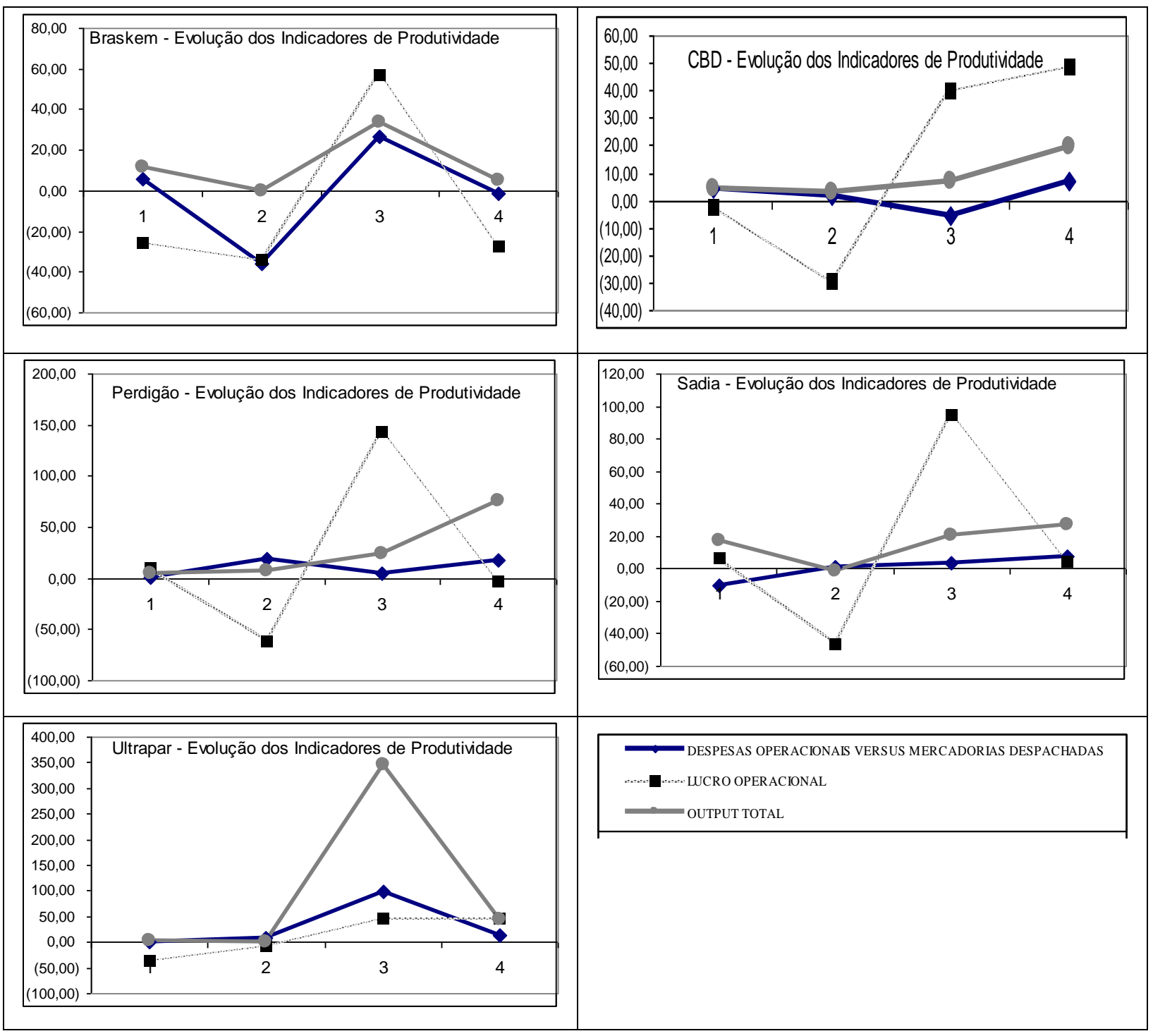

Quadro 4 - Indicadores de Desempenho Logístico de Produtividade - Cluster 1 
Desempenho Logístico de Produtividade em Companhias Brasileiras Listadas na Bolsa de Nova lorque na Perspectiva do Modelo World Class Logistics Helton Cristian de Paula, Joyce Menezes da Fonseca Tonin, Ramon Kael Benassi Bachmann, Romualdo

$\mathrm{Na}$ análise conjunta dos indicadores de Desempenho Logístico de Produtividade do Cluster 1 pode-se observar comportamento semelhante das Despesas Operacionais versus Mercadorias Despachadas e do Output Total. A única exceção ocorre para a companhia Ultrapar, que no período 3 apresenta um aumento desproporcional do Output Total. O Lucro Operacional das companhias apresentou grandes variações, com destaque para o biênio 2006/2007 que apresentou evolução para todas as companhias. Esta evolução só teve continuidade na CBD no biênio seguinte. O cluster 2 foi composto por 8 (oito) empresas: Ambev, Aracruz, CSN, Cosan, Embraer, Gafisa, Gerdau e VCPA. Para viabilizar a apresentação gráfica da análise descritiva, optou-se por segmentá-la em dois grupos. Desse modo, primeiro analisaram-se as companhias Ambev, Aracruz, CSN e Cosan (subgrupo A) e depois as companhias Embraer, Gafisa, Gerdau e VCPA (subgrupo B). Na Tabela 7 apresentam-se os indicadores de Desempenho Logístico de Produtividade do subgrupo A do Cluster 2. 
Desempenho Logístico de Produtividade em Companhias Brasileiras Listadas na Bolsa de Nova lorque na Perspectiva do Modelo World Class Logistics Helton Cristian de Paula, Joyce Menezes da Fonseca Tonin, Ramon Kael Benassi Bachmann, Romualdo Douglas Colauto

Tabela 7 - Indicadores de Desempenho Logístico de Produtividade - Subgrupo A - Cluster 2

\begin{tabular}{|c|c|c|c|c|}
\hline AMBEV & $\mathbf{2 0 0 4 / 2 0 0 5}$ & $\mathbf{2 0 0 5 / 2 0 0 6}$ & $\mathbf{2 0 0 6 / 2 0 0 7}$ & $\mathbf{2 0 0 7 / 2 0 0 8}$ \\
\hline $\begin{array}{c}\text { DESPESAS OPERACIONAIS VERSUS } \\
\text { MERCADORIAS DESPACHADAS }\end{array}$ & $\mathbf{3 , 3 4}$ & $(2,74)$ & 4,77 & 5,88 \\
\hline LUCRO OPERACIONAL & 32,78 & 38,94 & 5,94 & 0,63 \\
\hline OUTPUT TOTAL & 16,12 & 11,58 & 14,85 & 8,59 \\
\hline ARACRUZ & $\mathbf{2 0 0 4 / 2 0 0 5}$ & $\mathbf{2 0 0 5 / 2 0 0 6}$ & $\mathbf{2 0 0 6 / 2 0 0 7}$ & $\mathbf{2 0 0 7 / 2 0 0 8}$ \\
\hline $\begin{array}{c}\text { DESPESAS OPERACIONAIS VERSUS } \\
\text { MERCADORIAS DESPACHADAS }\end{array}$ & $(1,56)$ & $(1,91)$ & $(19,48)$ & 59,62 \\
\hline LUCRO OPERACIONAL & $(14,62)$ & 3,85 & $(5,85)$ & $(43,29)$ \\
\hline OUTPUT TOTAL & 2,85 & 22,55 & 4,73 & 0,22 \\
\hline CSN & $\mathbf{2 0 0 4 / 2 0 0 5}$ & $\mathbf{2 0 0 5 / 2 0 0 6}$ & $\mathbf{2 0 0 6 / 2 0 0 7}$ & $\mathbf{2 0 0 7 / 2 0 0 8}$ \\
\hline $\begin{array}{c}\text { DESPESAS OPERACIONAIS VERSUS } \\
\text { MERCADORIAS DESPACHADAS }\end{array}$ & $(14,58)$ & 92,68 & $(16,92)$ & 35,01 \\
\hline LUCRO OPERACIONAL & $(2,00)$ & $(28,21)$ & 35,05 & 167,93 \\
\hline OUTPUT TOTAL & 3,57 & 6,47 & 17,57 & 12,27 \\
\hline COSAN & $\mathbf{2 0 0 4 / 2 0 0 5}$ & $\mathbf{2 0 0 5 / 2 0 0 6}$ & $\mathbf{2 0 0 6 / 2 0 0 7}$ & $\mathbf{2 0 0 7 / 2 0 0 8}$ \\
\hline $\begin{array}{c}\text { DESPESAS OPERACIONAIS VERSUS } \\
\text { MERCADORIAS DESPACHADAS }\end{array}$ & 0,00 & 26,63 & $(4,95)$ & 0,32 \\
\hline LUCRO OPERACIONAL & 0,00 & 34,56 & 123,68 & $(190,79)$ \\
\hline OUTPUT TOTAL & 0,00 & 30,91 & 42,81 & $-5,37$ \\
\hline
\end{tabular}

Fonte: elaborado pelos autores.

O indicador de Despesas Operacionais versus Mercadorias Despachadas da Ambev apresentou pequenas variações que não ultrapassaram 9\%. A Aracruz mostra sistemáticas retrações nesse indicador, com exceção do biênio 2007/2008 quando foi registrado aumento de cerca de $60 \%$. A CSN foi a empresa que registrou altas significativas, cerca de $93 \%$ no biênio 2005/2006 e 35\% no biênio 2007/2008. O Lucro Operacional da Ambev obteve expressivos avanços, superiores a $30 \%$ nas duas primeiras observações, porém fechou a série histórica bem próxima da estabilidade. A Aracruz mostra retração do Lucro na maioria das observações, sendo a última delas superior a $43 \%$. A CSN apresentou duas retrações seguidas do Lucro Operacional. Entretanto, a companhia revelou recuperação no biênio 2007/2008, com aumento de $168 \%$ no indicador. A Cosan foi a empresa que reportou maior oscilação de performance do Lucro. Houve aumento de $123 \%$ no biênio 2006/2007; porém, no período subsequente houve retração de $190 \%$. O Output Total de todas as empresas registrou 
Desempenho Logístico de Produtividade em Companhias Brasileiras Listadas na Bolsa de Nova lorque na Perspectiva do Modelo World Class Logistics Helton Cristian de Paula, Joyce Menezes da Fonseca Tonin, Ramon Kael Benassi Bachmann, Romualdo Douglas Colauto

aumento, com destaque para a Cosan, que registrou as duas maiores altas, cerca de $30 \%$ e $43 \%$, e a única retração entre as empresas analisadas no período (cerca de $5 \%$ no biênio 2007/2008). Os gráficos para demonstrar as variações são apresentados no Quadro 5.

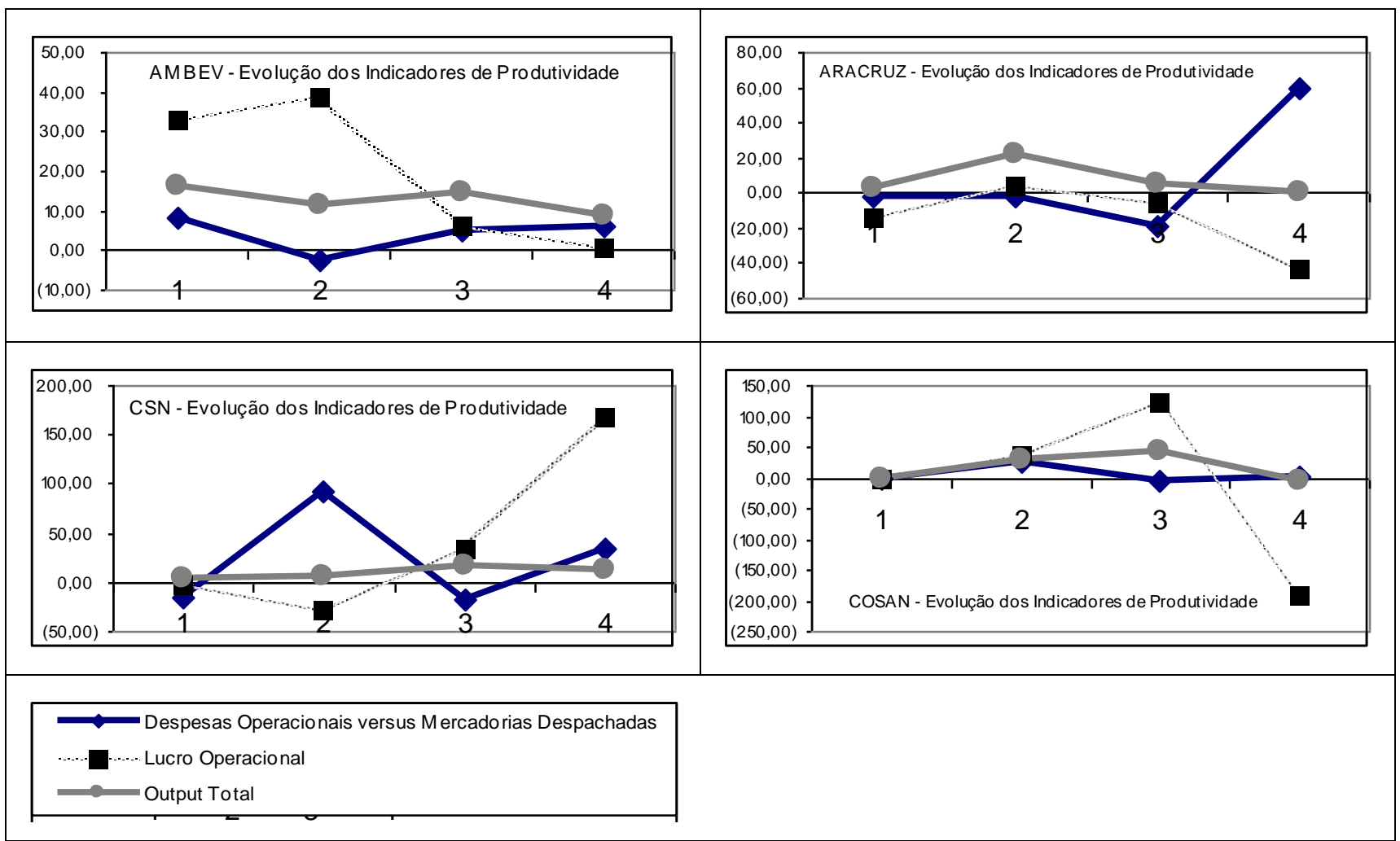

Quadro 5 - Indicadores de Desempenho Logístico de Produtividade - Subgrupo A - Cluster 2 Fonte: Elaborado pelos autores.

Todas as empresas apresentaram tendência de queda no Lucro Operacional, com exceção da CSN, que registrou expressivo avanço na última observação da série histórica. O indicador de Despesas Operacionais versus Mercadorias Despachadas da CSN foi o que apresentou maiores oscilações. O mesmo indicador da Ambev permaneceu em níveis praticamente estáveis. A Aracruz apresentou resultados favoráveis nos três primeiros biênios, revelando pior desempenho em 2007/2008 com o aumento do indicador. Já a Cosan mostrou grande aumento apenas no biênio $2005 / 2006$. 
Desempenho Logístico de Produtividade em Companhias Brasileiras Listadas na Bolsa de Nova lorque na Perspectiva do Modelo World Class Logistics Helton Cristian de Paula, Joyce Menezes da Fonseca Tonin, Ramon Kael Benassi Bachmann, Romualdo Douglas Colauto

Quanto ao indicador Output Total, a Ambev e a CSN não obtiveram grandes variações na série. As maiores variações foram nas companhias Aracruz, de 22,55\% no biênio de 2005/2006 e na Cosan, de 42,81\% no biênio 2006/2007. Na Tabela 8 apresenta-se a evolução dos indicadores de Desempenho Logístico de Produtividade das demais empresas do Cluster 2, as quais foram alocadas no subgrupo B.

Tabela 8 - Indicadores de Desempenho Logístico de Produtividade - Subgrupo B - Cluster 2

\begin{tabular}{|c|c|c|c|c|}
\hline EMBRAER & 2004/2005 & $2005 / 2006$ & 2006/2007 & $2007 / 2008$ \\
\hline $\begin{array}{c}\text { DESPESAS OPERACIONAIS VERSUS MERCADORIAS } \\
\text { DESPACHADAS }\end{array}$ & $(12,46)$ & 19,95 & $(28,98)$ & $(26,93)$ \\
\hline LUCRO OPERACIONAL & $(54,36)$ & $(31,21)$ & $(3,53)$ & 111,11 \\
\hline OUTPUTTOTAL & 1,90 & $(9,53)$ & 37,70 & 9,06 \\
\hline GAFISA & $2004 / 2005$ & $2005 / 2006$ & $2006 / 2007$ & $2007 / 2008$ \\
\hline $\begin{array}{c}\text { DESPESAS OPERACIONAIS VERSUS MERCADORIAS } \\
\text { DESPACHADAS }\end{array}$ & $(60,49)$ & 15,23 & $(23,65)$ & $(12,12)$ \\
\hline LUCRO OPERACIONAL & $(1,51)$ & $(2,01)$ & 136,32 & $(9,82)$ \\
\hline OUTPUT TOTAL & 4,15 & 44,17 & 54,25 & 51,88 \\
\hline GERDAU & $2004 / 2005$ & $2005 / 2006$ & $2006 / 2007$ & $2007 / 2008$ \\
\hline $\begin{array}{c}\text { DESPESAS OPERACIONAIS VERSUS MERCADORIAS } \\
\text { DESPACHADAS }\end{array}$ & 9,88 & 13,37 & 4,26 & 15,37 \\
\hline LUCRO OPERACIONAL & $(15,51)$ & 2,74 & 11,48 & 66,31 \\
\hline OUTPUT TOTAL & 15,13 & 6,35 & 27,06 & 34,21 \\
\hline VCPA & $2004 / 2005$ & $2005 / 2006$ & $2006 / 2007$ & $2007 / 2008$ \\
\hline $\begin{array}{c}\text { DESPESAS OPERACIONAIS VERSUS MERCADORIAS } \\
\text { DESPACHADAS }\end{array}$ & 40,21 & $(7,98)$ & 6,61 & $(14,33)$ \\
\hline LUCRO OPERACIONAL & $(39,11)$ & 9,14 & $(52,75)$ & $(11,35)$ \\
\hline OUTPUT TOTAL & 17,60 & 16,25 & $(11,12)$ & $(2,75)$ \\
\hline
\end{tabular}

Fonte: elaborado pelos autores.

As Despesas Operacionais versus Mercadorias Despachadas registraram grandes retrações em todas as empresas, no caso da Gafisa chegando até $60 \%$ no início da série histórica. A exceção foi o comportamento da Gerdau que registrou alta em todas as observações. O Lucro Operacional iniciou com retração para as companhias, chegando a cerca de $40 \%$ na VCPA e 55\% na Embraer. Nos períodos subsequentes, a Gerdau apresentou evoluções seguidas, apesar dos maiores avanços serem reportados pela Gafisa no biênio 2006/2007 (136\%) e pela Embraer em 2007/2008 (111\%). O 
Desempenho Logístico de Produtividade em Companhias Brasileiras Listadas na Bolsa de Nova lorque na Perspectiva do Modelo World Class Logistics Helton Cristian de Paula, Joyce Menezes da Fonseca Tonin, Ramon Kael Benassi Bachmann, Romualdo Douglas Colauto

Output Total mostra alta em todos os períodos de quase todas as empresas. A Embraer apresentou retração de cerca de 10\% no biênio 2005/2006 e a VCPA reportou retração no biênio 2006/2007 e 2007/2008, sendo o primeiro deles de 11\%. Importante destacar o comportamento da Gafisa, que registrou avanços superiores a $50 \%$ nos dois últimos períodos observados. Para facilitar a visualização das variações, apresentam-se os gráficos no Quadro 6.

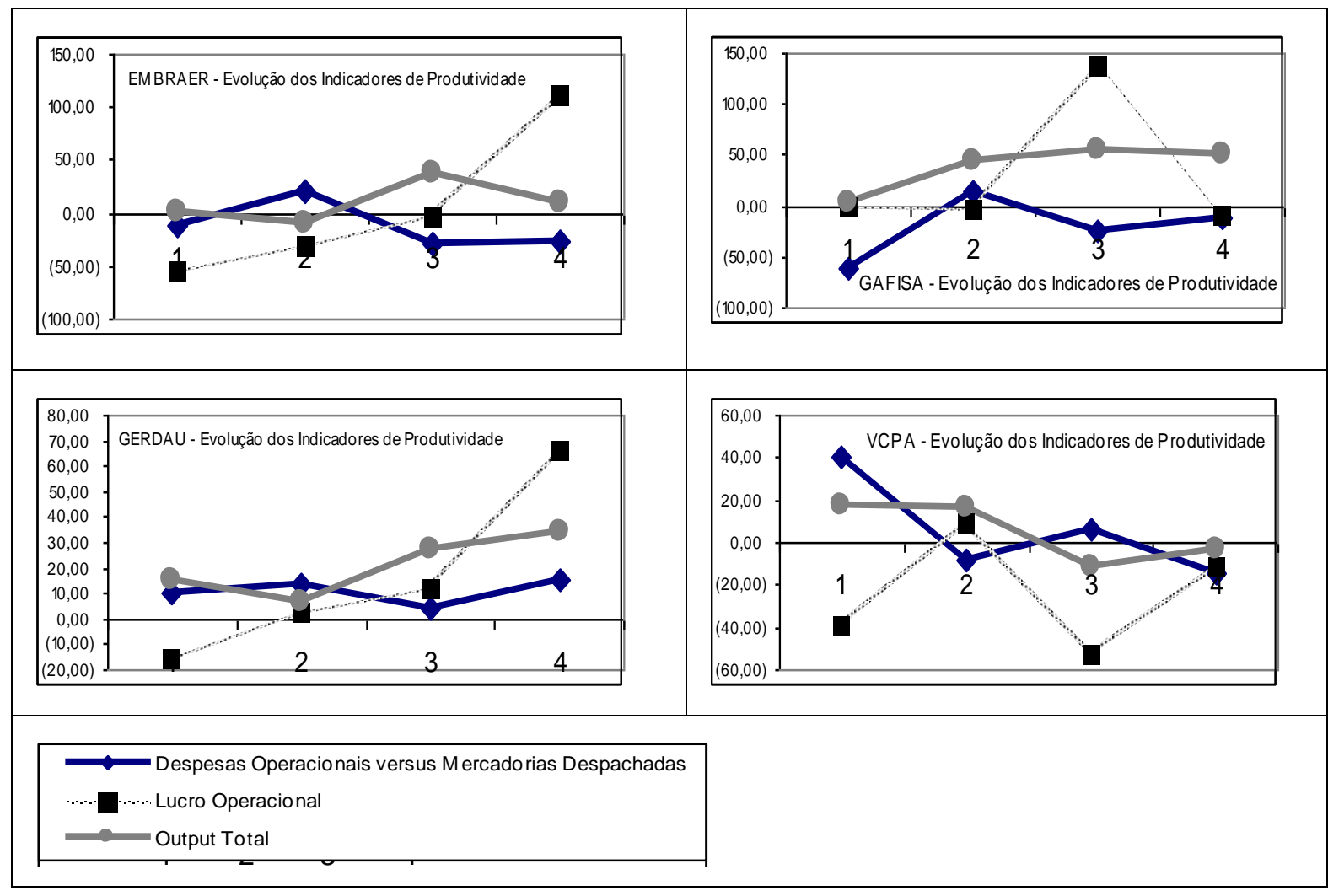

Quadro 6 - Indicadores de Desempenho Logístico de Produtividade - Subgrupo B - Cluster 2 Fonte: elaborado pelos autores.

O indicador Despesas Operacionais versus Mercadorias Despachadas apresenta comportamento semelhante ao do Output Total, embora somente a Gafisa registre regularidade na tendência dos dois. O Lucro Operacional registrou significativo avanço no caso da Embraer e da Gerdau no biênio 2007/2008, sendo que no caso da Gafisa e da VCPA registrou relativa estabilidade no mesmo período. Na Tabela 9 são apresentados os indicadores de Desempenho Logístico de Produtividade para o Cluster 
Desempenho Logístico de Produtividade em Companhias Brasileiras Listadas na Bolsa de Nova Iorque na Perspectiva do Modelo World Class Logistics Helton Cristian de Paula, Joyce Menezes da Fonseca Tonin, Ramon Kael Benassi Bachmann, Romualdo Douglas Colauto

3.

Tabela 9 - Indicadores de Desempenho Logístico de Produtividade - Cluster 3

\begin{tabular}{|c|c|c|c|c|}
\hline PETROBRAS & $\mathbf{2 0 0 4 / 2 0 0 5}$ & $\mathbf{2 0 0 5 / 2 0 0 6}$ & $\mathbf{2 0 0 6 / 2 0 0 7}$ & $\mathbf{2 0 0 7 / 2 0 0 8}$ \\
\hline $\begin{array}{c}\text { DESPESAS OPERACIONAIS VERSUS } \\
\text { MERCADORIAS DESPACHADAS }\end{array}$ & 28,56 & 1,38 & $\mathbf{2 6 , 9 7}$ & $(\mathbf{2 0 , 7 7 )}$ \\
\hline LUCRO OPERACIONAL & 31,33 & 5,24 & $(11,37)$ & $\mathbf{3 2 , 9 4}$ \\
\hline OUTPUT TOTAL & 13,55 & 18,62 & $\mathbf{7 , 2 2}$ & $\mathbf{2 6 , 9 1}$ \\
\hline VALE & $\mathbf{2 0 0 4 / 2 0 0 5}$ & $\mathbf{2 0 0 5 / 2 0 0 6}$ & $\mathbf{2 0 0 6 / 2 0 0 7}$ & $\mathbf{2 0 0 7 / 2 0 0 8}$ \\
\hline $\begin{array}{c}\text { DESPESAS OPERACIONAIS VERSUS } \\
\text { MERCADORIAS DESPACHADAS }\end{array}$ & $(35,27)$ & 35,15 & 21,11 & 102,41 \\
\hline LUCRO OPERACIONAL & 36,81 & 35,24 & 45,93 & $(6,53)$ \\
\hline OUTPUT TOTAL & 13,27 & 25,71 & 42,75 & 8,44 \\
\hline
\end{tabular}

Fonte: elaborado pelos autores.

Os indicadores de Desempenho em Produtividade apresentam grandes variações ao longo do período analisado. As Despesas Operacionais da Petrobras apresentaram aumento superior a $25 \%$ em dois dos períodos avaliados, apresentando pequena alta no biênio 2005/2006 e queda significativa superior a $20 \%$ na última observação. A Vale inicia a série com redução aproximada de 35\%; segue com aumento aproximado de $35 \%$; e novo aumento superior a $20 \%$; as Despesas Operacionais versus Mercadorias Despachadas duplicaram no último período analisado.

O Lucro Operacional das companhias ao longo do período mostra aumentos significativos. A Petrobras inicia a série com aumento desse indicador em $30 \%$; seguido de novo aumento em 5\%. Em 2006/2007 houve retração superior a 10\% e na última observação houve aumento de $30 \%$. A Vale apresentou expansão significativa ao nível de $35 \%$ nos dois primeiros períodos, se aproximou de 50\% no biênio 2006/2007 e, no último período, retraiu. O Output Total evoluiu em todos os períodos para as duas companhias. Os avanços foram significativos, superando $10 \%$ em quase todos os períodos e, no caso da Vale, supera 40\% em 2006/2007. Os três indicadores de Desempenho Logístico de Produtividade ao longo da série histórica apresentaram comportamento bem definido. O Output Total manteve a trajetória de aumento, indiferente da variação do Lucro Operacional ou das Despesas Operacionais versus 
Desempenho Logístico de Produtividade em Companhias Brasileiras Listadas na Bolsa de Nova lorque na Perspectiva do Modelo World Class Logistics Helton Cristian de Paula, Joyce Menezes da Fonseca Tonin, Ramon Kael Benassi Bachmann, Romualdo Douglas Colauto

Mercadorias Despachadas. As Despesas Operacionais versus Mercadorias Despachadas apresentaram aumentos significativos, havendo apenas um período de retração em cada companhia. Todavia, o Lucro Operacional, mesmo com a expansão do indicador Despesas Operacionais versus Mercadorias Despachadas e do Output Total também registrou avanço, o que denota pouca influência dos outros dois indicadores em seu comportamento. O Quadro 7 apresenta a evolução dos indicadores para as companhias do cluster 3.

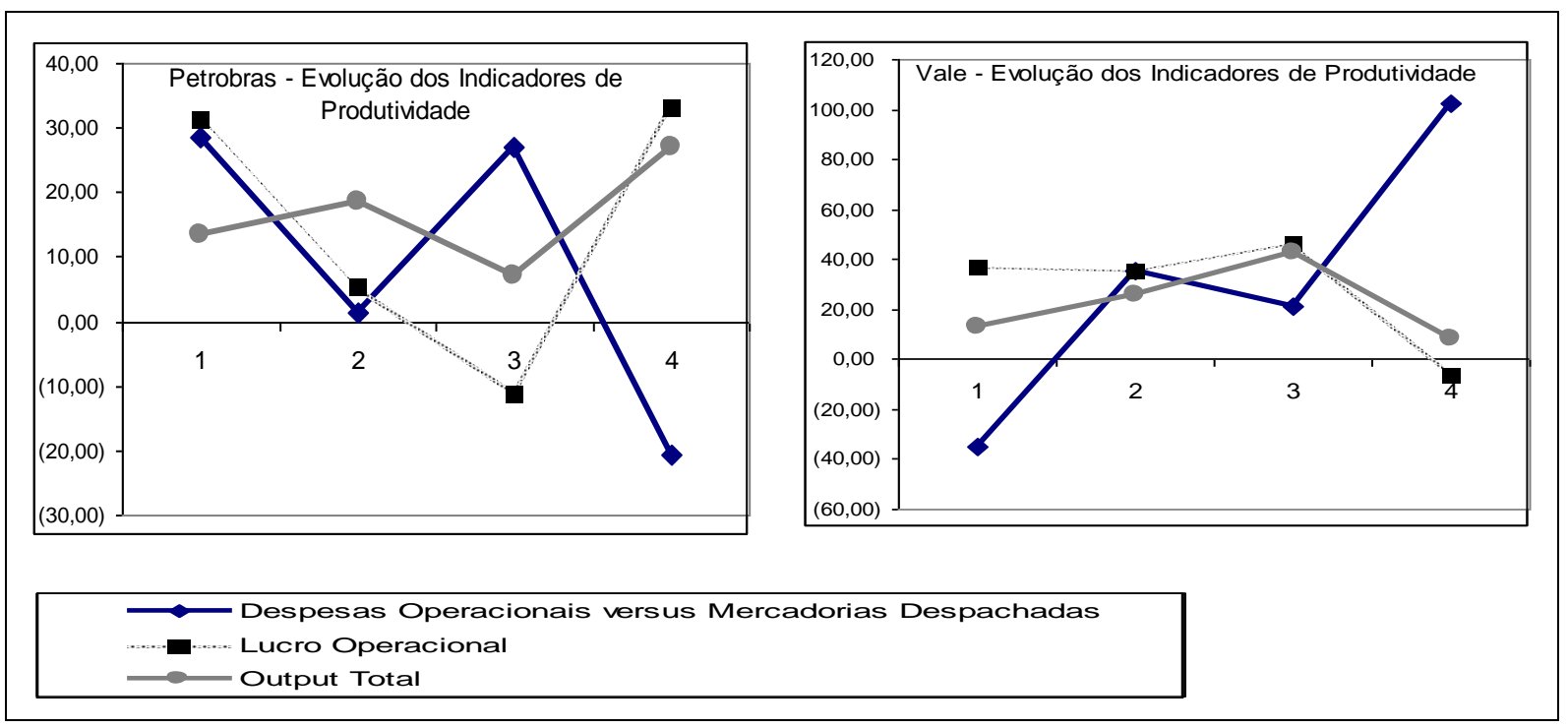

Quadro 7 - Indicadores de Desempenho Logístico de Produtividade - Cluster 3

Fonte: elaborado pelos autores.

Nota-se oscilação no comportamento dos Indicadores de Desempenho Logístico de Produtividade em ambas as companhias. O Output Total registra aumento sistemático ao longo do período avaliado, apesar de apresentar redução na intensidade do aumento, no caso da Petrobras no biênio 2006/2007 e no caso da Vale no biênio subsequente. $O$ indicador Despesas Operacionais versus Mercadorias Despachadas são ponto de destaque, devido às fortes variações. O gráfico evidencia uma tendência de queda do Lucro Operacional da Petrobras, que só é revertida no último período da série, com registro de expressiva expansão. A Vale registra estabilidade desse indicador, que se manteve com aumento regular de cerca de $40 \%$ nos três períodos 
Desempenho Logístico de Produtividade em Companhias Brasileiras Listadas na Bolsa de Nova lorque na Perspectiva do Modelo World Class Logistics Helton Cristian de Paula, Joyce Menezes da Fonseca Tonin, Ramon Kael Benassi Bachmann, Romualdo Douglas Colauto

iniciais, contudo finalizou a série histórica com retração.

\section{CONCLUSÃo}

O modelo World Class Logistics foi desenvolvido por um grupo de pesquisadores da Universidade de Michigan com o propósito de mapear os procedimentos no setor de logística das empresas com performance diferenciada. $O$ modelo prevê o acompanhamento de quatro competências fundamentais: (a) Posicionamento, (b) Integração, (c) Agilidade e (d) Mensuração. Avaliar o desempenho das três primeiras competências requer conhecer o planejamento estratégico das empresas e ter acesso a dados gerenciais internos. Para a competência Mensuração, diversos autores, como Bowersox et al. (1989), Stock e Lambert (2001), Mentzer et al. (1996), Fleury e Lavalle (1997), Stainer (1997), Franzelle (2001), Bowersox e Closs (2001) sugeriram um conjunto de indicadores para compor o referido o modelo, sendo que alguns têm íntima conexão com a contabilidade.

Bowersox et al. (1989) mostram que na pesquisa Leading Edge Logistics: competitive positioning for the 1990's as medidas de desempenho empregadas pelas empresas de classe mundial pertencem às seguintes áreas: (1) Custo; (2) Serviço ao Cliente e Qualidade; (3) Produtividade; e (4) Gerenciamento de Ativos.

Nesse sentido, com foco na competência Mensuração, mais especificamente na área de Produtividade, o objetivo geral da pesquisa consistiu em apresentar a evolução do desempenho logístico de produtividade em companhias brasileiras com ações negociadas na Bolsa de Nova lorque no período de 2004 a 2008, na concepção do modelo World Class Logistics.

Para operacionalizar os indicadores aplicando-os em empresas brasileiras, o estudo culminou em uma amostra de 15 companhias brasileiras com ações negociadas na Bolsa de Valores de Nova lorque. Para analisar o desempenho logístico de produtividade das companhias, de 2004 a 2008, utilizou-se estatística descritiva segmentada em clusters. Assim, realizou-se análise individualizada das companhias de cada conglomerado, verificando-se a evolução dos indicadores por meio da média 
Desempenho Logístico de Produtividade em Companhias Brasileiras Listadas na Bolsa de Nova lorque na Perspectiva do Modelo World Class Logistics Helton Cristian de Paula, Joyce Menezes da Fonseca Tonin, Ramon Kael Benassi Bachmann, Romualdo Douglas Colauto

móvel.

A análise dos dados mostrou que as empresas Braskem, CBD, Perdigão, Sadia e Ultrapar, que compuseram o cluster 1, não obtiveram bom desempenho nos indicadores Logísticos de Produtividade de forma geral. As empresas Ambev, Aracruz, CSN, Cosan, Embraer, Gafisa, Gerdau e VCPA, que formam o cluster 2, se destacaram nos indicadores Despesas Operacionais versus Mercadorias Despachadas e Output Total. Entretanto, o cluster 3, composto pelas empresas Petrobras e Vale, foi o que apresentou melhor desempenho geral nos indicadores Logísticos de Produtividade. Isso ocorreu devido ao alto crescimento do Lucro Operacional ter superado o pior resultado decorrente do crescimento dos outros dois indicadores, que são do tipo quanto menor melhor.

O indicador Despesas Operacionais versus Mercadorias Despachadas do cluster 1, em relação aos outros dois clusters, apresentou-se desfavorável pois, dentre outros fatores, todas as empresas, com exceção da Braskem, obtiveram aumento ao longo da série. Em relação ao cluster 2, a Embraer e a Gafisa foram as empresas que revelaram queda na série como um todo, tornando este cluster o de melhor desempenho neste indicador. Já o cluster 3 apresentou aumento para a Petrobras e a Vale, constituindo o pior desempenho neste indicador.

Quanto ao Lucro Operacional, o cluster 3 obteve o melhor resultado, proveniente dos crescimentos sucessivos deste indicador para a Petrobras e a Vale. No cluster 1, a Braskem foi a única empresa que mostrou queda no Lucro Operacional ao longo da série. O cluster 2, por sua vez, apresentou o pior resultado neste indicador pois, dentre as oito empresas, apenas quatro registraram aumento geral ao longo da série (Ambev, CSN, Gafisa e Gerdau).

O indicador Output Total, que expressa o somatório de todos os custos de insumos, incluindo mercadorias, mão-de-obra e depreciação, expressou melhor desempenho para as companhias do cluster 2 pois, apesar de os indicadores de todas as empresas terem crescido de forma geral na série histórica, este cluster teve menor crescimento. $O$ cluster 3 também mostrou crescimento para este indicador, o que não é 
Desempenho Logístico de Produtividade em Companhias Brasileiras Listadas na Bolsa de Nova lorque na Perspectiva do Modelo World Class Logistics Helton Cristian de Paula, Joyce Menezes da Fonseca Tonin, Ramon Kael Benassi Bachmann, Romualdo Douglas Colauto

favorável; e o cluster 1 foi o que obteve o pior desempenho de Output Total, principalmente devido ao grande crescimento do indicador da Ultrapar.

A avaliação dos indicadores de Desempenho Logístico denota ser útil as empresas, podendo assessorar na avaliação de concorrentes e principalmente na criação de padrão de referência, questões importantes no processo de tomada de decisões. Como sugestão para pesquisas futuras propõe-se testar os indicadores de desempenho logístico de produtividade, em séries históricas maiores e em empresas que negociam em outras bolsas de valores.

\section{REFERÊNCIAS}

ANDEL, Tom. (1997). How to beat costs at hide and seek. Transportation and Distribution Review, EUA.

ANDERSSON, P, ARONSSON, H, STORHAGEN, N. (1989). Measuring logistics performance. Engineering Costs and Production Economics, v. 17, p. 253-262.

BOWERSOX, D., DAUGHERTY, P., DROGE, C., ROGERS, D., WRADLOW, D. (1989). Leading edge logistics competitive positioning for the 1990's. Council of Logistics Management, Oak Brook, IL.

BOWERSOX, Donald J. CLOSS, David. J. (2001). Logística empresarial: o processo de integração da cadeia de suprimento. São Paulo: Atlas.

CHOW, G., HEAVER, T., HENRIKSSON, L. (1994). Logistics Performance: Definition and Measurement. International Journal of Physical Distribution \& Logistics Management, v. 24, p. 17-28.

COOPER, D. R.; SCHINDLER, P. S. (2003). Métodos de pesquisa em administração. (7 ed.). Porto Alegre: Bookman.

COSTA, L. VIEIRA, L. FLEURY, P.F. (2002). Contract logistics in Brazil, Booz Allen Hamilton.

FARIA, Ana Cristina de; COSTA, Maria de Fátima Gameiro da. (2005). Gestão de Custos Logísticos. São Paulo: Atlas.

FLEURY, P.F.; LAVALLE, C. (2000). Avaliação do serviço de distribuição física: a relação entre a indústria de bens de consumo e o comércio atacadista e varejista. In: 
Desempenho Logístico de Produtividade em Companhias Brasileiras Listadas na Bolsa de Nova lorque na Perspectiva do Modelo World Class Logistics Helton Cristian de Paula, Joyce Menezes da Fonseca Tonin, Ramon Kael Benassi Bachmann, Romualdo

FLEURY, P.; WANKE, P.; FIGUEIREDO, K. (org.). Logística empresarial: a perspectiva brasileira. São Paulo: Atlas. p. 76-89.

FRANZELLE, E. (2001). Supply Chain Strategy: the logistics of supply chain management. New York: McGraw-Hill, 2001.357p

GERVÁSIO, M. H.; HIIJAR, M. F.; FIGUEIREDO, K. F. (2005). Mensuração de desempenho logístico e o modelo World Class Logistics and Tecnologístic, Ago./set. Disponível em: <www.cel.coppead.ufrj.br>.

HAIR, Joseph F. Tatham et al. (2005). Multivariate Data Analysis. 5. ed. Prentice-Hall, Inc.

IMAM - Inovação e Melhoramento na Administração Moderna. Disponível em: <http://www.imam.com.br/logistica/arquivos/PDF_PESQUISAS/LOGISTICA2003.PDF>. Acessado em: 20/maio2009.

LAMBERT, D., STOCK, J. (1993). Strategic Logistics Management. (3 ed.). USA: Irwin.

MENTZER, J., KONRAD, B. (1991). An efficiency/effectiveness approach to logistics performance analysis. Journal of Business Logistics, v. 12, n. 1.

RICHARDSON, R. J. (1999). Pesquisa Social: métodos e técnicas. (3 ed.). São Paulo: Atlas.

SLACK, N., LEWIS, M. (2003). Operations strategy. Pearson Education: New Jersey.

STAINER, A. (1997). Logistics: a productivity and performance perspective. Supply Chain Management, v. 2, n. 2, p. 53-62.

STOCK, James; LAMBERT, Douglas M. (2001). Strategic logistics management. (4 ed.). New York: McGraw-Hill.

WIVES, L, K. (1999). Um estudo sobre agrupamentos de documentos textuais em processamento de informações não estruturadas usando técnicas de Clustering. (Dissertação de Mestrado). Instituto de Informática. Programa de Pós-Graduação em Computação. Universidade Federal do Rio Grande do Sul.

Data de Submissão: 29/11/2011

Data de Aceite: 20/12/2011 